\title{
Inherited FGFR2 mutation in a Chinese patient with Crouzon syndrome and luxation of bulbus oculi provoked by trauma: a case report
}

\author{
Ji Yang ${ }^{1,2,3^{*}+}$, Tao Tao ${ }^{1,2,3+}$, Hai Liu ${ }^{1,2,3}$ and Zhu-Lin $\mathrm{Hu}^{1,2,3}$
}

\begin{abstract}
Background: Crouzon syndrome (CS), which results from fibroblast growth factor receptor 2 mutations, is associated with craniosynostosis, exophthalmos, and other symptoms. Herein, we report the genetic abnormalities detected in a Chinese family with autosomal dominant CS, combined with luxation of the eyeball. This luxation was a consequence of the trauma to the shallow orbits.

Case presentation: The proband was a 4-year-old boy. He accidentally fell, following which luxation of the bulbus oculi occurred immediately. Computed tomography and magnetic resonance imaging clearly revealed ocular proptosis. Upon physical examination, the proband, his father, and grandfather had ocular proptosis, shallow orbits, and mid-face hypoplasia. However, their hands and feet were clinically normal. Genomic DNA was extracted from the peripheral blood through a polymerase chain reaction performed for the target sequence. Genetic assessments revealed a heterozygous missense mutation (c.1012G > C, p.G338R) in exon 10 of the human FGFR2, cosegregated with the disease phenotype in this family. These findings confirmed the diagnosis of CS.

Discussion: CS is usually caused by FGFR2 mutations. While there are a few reports of luxation of the bulbus oculi in Chinese families with CS, the ocular proptosis, shallow orbits, combined with luxation of eyeball after trauma observed in this patient were particularly interesting. Our findings enhance the current knowledge of traumatic luxation concomitant with CS.
\end{abstract}

Keywords: Crouzon syndrome, Luxation of eyeball, Mutation screening, FGFR2

\section{Background}

Crouzon syndrome (CS), caused by fibroblast growth factor receptor 2 (FGFR2) mutations, is associated with craniosynostosis. The incidence is approximately $16.5 / 1$, 000,000 [1]. The common manifestations of CS include brachycephaly, exophthalmos, divergent strabismus to ocular hypertelorism, and mandibular prognathism. Heterozygous mutations of FGFR2, located at 10q26, have been identified in autosomal dominant CS. The FGFR2

\footnotetext{
* Correspondence: 827859119@qq.com

${ }^{\dagger} \mathrm{Ji}$ Yang and Tao Tao contributed equally to this work.

'Department of Ophthalmology, Second people's hospital of Yunnan province, Kunming 650000, China

${ }^{2}$ The eye disease clinical medical research center of Yunnan province,

Kunming 650000, China

Full list of author information is available at the end of the article
}

protein consists of three extracellular immunoglobulinlike (Ig) domains (Ig I, Ig II, and Ig III), a single transmembrane segment, and a cytoplasmic tyrosine kinase domain [2]. To the best of our knowledge, nearly 60 FGFR2 mutations have been identified in association with CS. Meanwhile, approximately $95 \%$ of mutations in CS occur in exon 8 and exon 10 of the FGFR2 gene. Each of these exons separately codes for the Ig IIIa (8) and Ig IIIc (10) domains [3]. We report the genetic abnormalities in a Chinese family with autosomal dominant CS combined with luxation of the eyeball in this study. It is noteworthy that the luxation in our patient was a sequela of trauma to the shallow orbits.

(c) The Author(s). 2019 Open Access This article is distributed under the terms of the Creative Commons Attribution 4.0 International License (http://creativecommons.org/licenses/by/4.0/), which permits unrestricted use, distribution, and reproduction in any medium, provided you give appropriate credit to the original author(s) and the source, provide a link to the Creative Commons license, and indicate if changes were made. The Creative Commons Public Domain Dedication waiver (http://creativecommons.org/publicdomain/zero/1.0/) applies to the data made available in this article, unless otherwise stated. 


\section{Case presentation}

A pedigree with CS was recruited for this study (Fig. 1a). The patient received a systemic evaluation, and we collected peripheral blood samples from the patient and his lineal relatives. This study adhered to the tenets of the Declaration of Helsinki. The ethics committee of The Second People's Hospital of Yunnan province approved the protocol, and we obtained written informed consent from all the study participants. Genomic DNA was extracted from the peripheral blood. Polymerase chain reaction (PCR) for the target sequence of FGFR2 was performed, according to the methods described previously [4].

The proband was a 4-year-old boy. He fell accidentally, following which luxation of the bulbus oculi occurred immediately (Fig. 1d). The patient's family brought him to our hospital for treatment. We observed that the patient's left eyeball was clearly dislocated and accompanied by hypophasis of the left eye. The eye movements were restricted in all directions. External strabismus was also observed. The relative afferent pupillary defect (RAPD) was negative. Upon physical examination, the proband (III:2), his father (II:3, 28 years old), and his grandfather (I:1, 54 years old) had ocular proptosis, shallow orbits, and mid-face hypoplasia, but clinically normal hands and feet (Fig. 1d). The boy's father and grandfather had normal vision, while displaying a 'surprised look'. The best corrected visual acuity (BCVA) of individual III:2 ( 4 years old) was 0.5 for the right eye, and 0.1 for the luxated left eye. The visual acuity of the left eye was in a precarious condition due to severe exposure keratitis and traumatic dislocation of the eyeball. The orbital pressure in left orbit was higher than that in the right orbit. Computed tomography and magnetic resonance imaging did not reveal retrobulbar hematoma and revealed shallow orbits and ocular proptosis in patient III:2 (Fig. 1b, c). Therefore, mannitol (10 g, q8h, intravenous drip) was administered for symptomatic reduction of orbital pressure for 3 days. At the same time, tobramycin eye ointment (topical instillation, qn) and carbomer eye drops (topical instillation, q8h) were administered to the left eye for 3 days to protect it from exposure keratitis and obstinate conjunctivitis. After treatment, the dislocated bulbus oculi reverted back to the orbit and left eyelid could be closed. The BCVA of the left eye increased to 0.2 (Fig. 1d). The restriction in eye movement improved after treatment. However, mild restricted internal eye movement and mild external strabismus were observed. The patient was re-examined at our hospital 1 week after discharge. There was no obvious dislocation of the eyeball. The BCVA of left eye was maintained at 0.2. Subsequently, the patient was lost to follow-up.

Genetic assessments revealed a heterozygous missense mutation (c.1012G > C, p.G338R) in exon 10 of the human FGFR2, cosegregated with the disease phenotype in this family (Fig. 2a). This mutation resulted in the replacement of hydrophilic glycine with more hydrophilic arginine at codon 338 (p. Gly338Arg) at the immunoglobulin (Ig)-like domain 3. Moreover, the missense mutation is not found in normal individuals, including II:4, who was the proband's mother.

To study the structure of the mutant FGFR2 protein, three-dimensional crystal structures of the wild-type and mutant FGFR2 (residues 1-520) were constructed based on the human FGFR2, with a sequence confidence of $100 \%$ and coverage of $59 \%$. Structural modeling of the FGFR2 protein (Fig. 2c) demonstrated that G338R was located in the $\beta$-sheet, which is required for receptor binding [5]. The mutated area was found in a highly conserved segment of the FGFR2 protein in humans and other species (Fig. 2b). We considered the variation as 'likely pathogenic' according to the standards and guidelines from American College of Medical Genetics and Genomics (ACMG), and 4 bioinformatics tools (SIFT, Mutation Taster, Polyphen2, REVEL) [6].
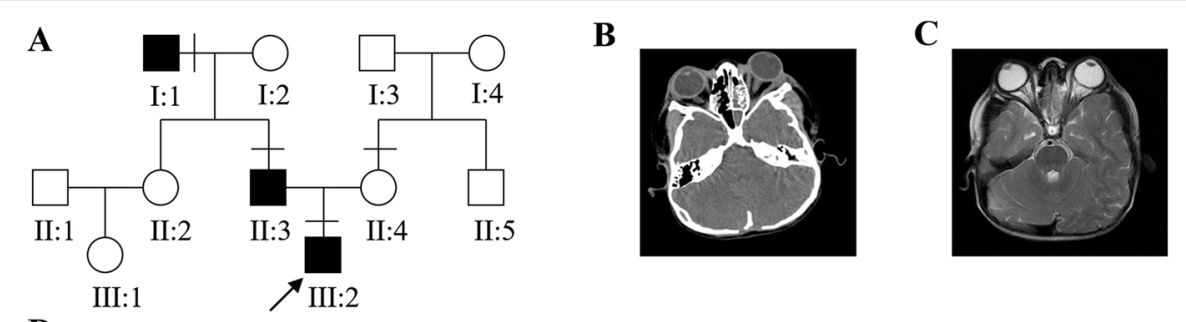

D

III:2

III:2 after treatment

II:3

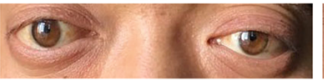

$\mathrm{I}: 1$

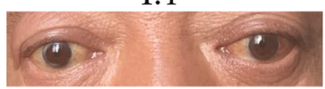

Fig. 1 Patients with Crouzon syndrome and clinical examination of the proband. a Three-generational Crouzon syndrome pedigree. Affected individuals are indicated by filled symbols and the proband is marked with an arrow. b, c Computed tomography and magnetic resonance imaging did not reveal retrobulbar hematoma and revealed shallow orbits and obvious ocular proptosis in the proband. $\mathbf{d}$ Facial photographs of patients with Crouzon syndrome 


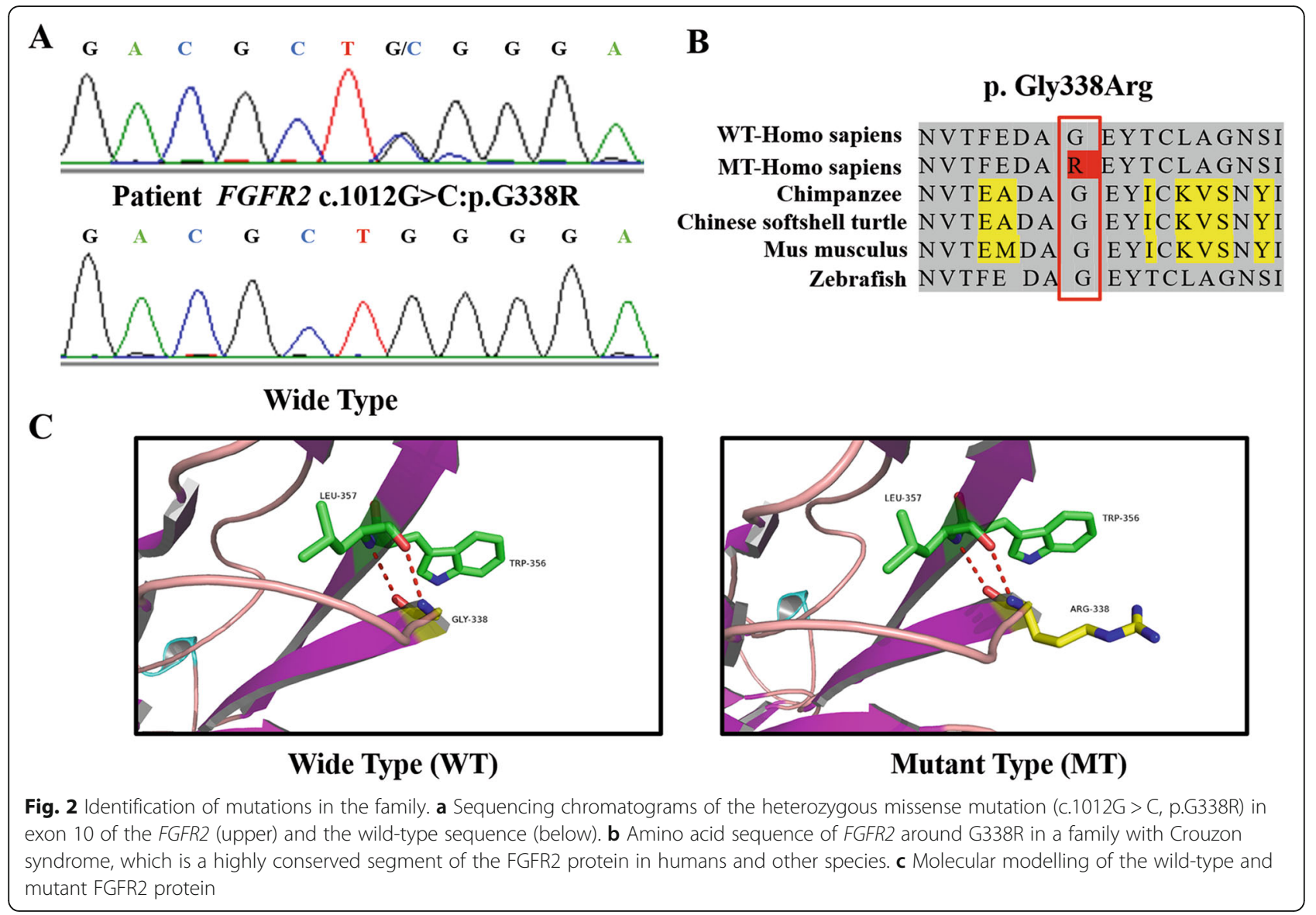

\section{Discussion}

CS is usually caused by FGFR 2 mutations and accounts for $4.8 \%$ of cases with craniosynostoses. CS is easily diagnosed when patients present with abnormal facial structures, especially exophthalmos and maxillary or mandibular prognathism, which can be visualized on fetal ultrasonography performed at 35 weeks of gestation, for orbital growth retardation [7]. For treatment, surgical intervention for the malformation of the skull in CS is recommended, in the presence of orbital proptosis and maxillary or mandibular prognathism [8]. Our patient presented with luxation of the bulbus oculi and hypophasis of the left eye. The treatment aimed to reduce orbital pressure and protect the affected eye from exposure keratitis and obstinate conjunctivitis. The symptoms were relieved and the BCVA increased after treatment.

In the present study, we reported the identification of a missense mutation (c.1012G > C, p.G338R) in a Chinese family with autosomal dominant CS. A few FGFR2 mutations have been found to affect osteoblast and chondrocyte cell proliferation in vitro [9]. At the same time, a minor change in FGFR2 can inevitably lead to primordial bone changes [10]. Furthermore, mutant-type FGFR2 (c.1012G > C) can affect craniofacial growth, by increasing alkaline phosphatase gene and osteocalcin gene expression, inevitably leading to CS [11]. The clinical characteristics of our patient supported a diagnosis of CS, while there are a few reports of luxation of the bulbus oculi in Chinese families with CS. It is of interest that our patient had ocular proptosis and shallow orbits, combined with luxation of the eyeball after trauma.

In conclusion, we identified a mutation in FGFR2 that caused CS [11, 12]. Edema of the periorbital tissue is observed in the event of blunt injuries to the forehead and periorbital area. The shallow orbits observed in patients with CS patients have limited space to accommodate edematous tissue. Therefore, these patients are more likely to develop eyeball luxation. Our findings enhance the current knowledge of CS concomitant with traumatic luxation of the eyeball.

\section{Abbreviations}

CS: Crouzon syndrome; FGFR2: Fibroblast growth factor receptor 2

\section{Acknowledgments}

We appreciate all patients and family members for their participation in this study.

\section{Authors' contributions}

JY designed and conducted the study. TT provided clinical care. HL, and ZLH analyzed and interpreted the patient data. JY and TT were major 
contributors in writing the manuscript. All authors read and approved the final manuscript.

\section{Funding}

This study was supported by the Yunnan provincial Major science and technology Foundation (Grant No.:2018ZF009); Yunnan provincial institute of ophthalmology, key laboratory of ophthalmology research (Grant No.:2017DG008); Yunnan provincial academician and leading talent training (Grant No:2017HC010); Yunnan provincial academician expert workstation (Grant No.:2017IC064). They supported in the data collection, interpretation and writing the manuscript.

\section{Availability of data and materials}

All data generated or analyzed in this report are included in this published article.

\section{Ethics approval and consent to participate}

This report was approved by the ethics committee at The Second People's Hospital of Yunnan province. The patient's legal guardian gave written, informed consent prior to undergoing this study.

\section{Consent for publication}

The risk of identification of the patient was minimized and the case patient's legal guardian gave written, informed consent for publication of this report.

\section{Competing interests}

The authors declare that they have no competing interests.

\section{Author details}

'Department of Ophthalmology, Second people's hospital of Yunnan province, Kunming 650000, China. ${ }^{2}$ The eye disease clinical medical research center of Yunnan province, Kunming 650000, China. ${ }^{3}$ The eye disease clinical medical center of Yunnan province, Kunming 650000, China.

Received: 21 June 2019 Accepted: 1 October 2019

Published online: 22 October 2019

\section{References}

1. Robin N H, Falk M J, Haldemanenglert C R. FGFR-Related Craniosynostosis Syndromes - GeneReviews ${ }^{\oplus}$ - NCBI Bookshelf [J]. Gene, 2011.

2. Miraoui $\mathrm{H}$, Marie PJ. Fibroblast growth factor receptor signaling crosstalk in skeletogenesis. Sci Signal. 2010;3(146):re9.

3. Kan SH, Elanko N, Johnson D, Cornejo-Roldan L, Cook J, Reich EW, Tomkins S, Verloes A, Twigg SR, Rannan-Eliya S, et al. Genomic screening of fibroblast growth-factor receptor 2 reveals a wide spectrum of mutations in patients with syndromic craniosynostosis. Am J Hum Genet. 2002;70(2):472-86.

4. Rao FQ, Cai XB, Cheng FF, Cheng W, Fang XL, Li N, Huang XF, Li LH, Jin ZB. Mutations in LRP5, FZD4, TSPAN12, NDP, ZNF408, or KIF11 Genes Account for $38.7 \%$ of Chinese Patients With Familial Exudative Vitreoretinopathy. Invest Ophthalmol Vis Sci. 2017:58(5):2623-9.

5. Li ZL, Chen X, Zhuang WJ, Zhao W, Liu YN, Zhang FX, Ha RS, Wu JH, Zhao $C$, Sheng XL. FGFR2 mutation in a Chinese family with unusual Crouzon syndrome. Int J Ophthalmol. 2016;9(10):1403-8.

6. Richards S, Aziz N, Bale S, Bick D, Das S, Gastier-Foster J, Grody WW, Hegde $M$, Lyon E, Spector $E$, et al. Standards and guidelines for the interpretation of sequence variants: a joint consensus recommendation of the American College of Medical Genetics and Genomics and the Association for Molecular Pathology. Genet Med. 2015;17(5):405-24.

7. Menashe $Y$, Ben Baruch G, Rabinovitch O, Shalev Y, Katzenlson MB, Shalev E. Exophthalmus--prenatal ultrasonic features for diagnosis of Crouzon syndrome. Prenat Diagn. 1989:9(11):805-8.

8. Hariri F, Cheung LK, Rahman ZA, Mathaneswaran V, Ganesan D. Monobloc Le fort III distraction osteogenesis for correction of severe fronto-orbital and midface hypoplasia in pediatric Crouzon syndrome. Cleft Palate Craniofac J. 2016;53(1):118-25

9. Fanganiello RD, Sertie AL, Reis EM, Yeh E, Oliveira NA, Bueno DF, Kerkis Alonso N, Cavalheiro S, Matsushita H, et al. Apert p.Ser252Trp mutation in FGFR2 alters osteogenic potential and gene expression of cranial periosteal cells. Mol Med. 2007;13(7-8):422-42.
10. Jabs EW, Li X, Scott AF, Meyers G, Chen W, Eccles M, Mao Jl, Charnas LR, Jackson CE, Jaye M. Jackson-Weiss and Crouzon syndromes are allelic with mutations in fibroblast growth factor receptor 2. Nat Genet. 1994;8(3):275-9.

11. Fan J, Li Y, Jia R, Fan X. An inherited FGFR2 mutation increased osteogenesis gene expression and result in Crouzon syndrome. BMC Med Genet. 2018;19(1):91.

12. Luong ALT, Ho TT, Hoang H, Nguyen TQ, Ho TC, Tran PD, Hoang TT, Nguyen NT, Chu HH. Detection of G338R FGFR2 mutation in a Vietnamese patient with Crouzon syndrome. Biomed Rep. 2019;10(2):107-12.

\section{Publisher's Note}

Springer Nature remains neutral with regard to jurisdictional claims in published maps and institutional affiliations.
Ready to submit your research? Choose BMC and benefit from:

- fast, convenient online submission

- thorough peer review by experienced researchers in your field

- rapid publication on acceptance

- support for research data, including large and complex data types

- gold Open Access which fosters wider collaboration and increased citations

- maximum visibility for your research: over $100 \mathrm{M}$ website views per year

At BMC, research is always in progress.

Learn more biomedcentral.com/submission 